\title{
A Case Study of River Rehabilitation for Fish in Northern Italy: The Panaro River Project
}

\author{
${ }^{1}$ Claudio Comoglio, ${ }^{2}$ Enrico Pini Prato, ${ }^{2}$ Mauro Ferri, ${ }^{3}$ Massimiliano Gianaroli \\ ${ }^{1}$ DITAG - Politecnico di Torino - C.so Duca degli Abruzzi 24, 10129 - Torino, Italy \\ ${ }^{2}$ DIAF - Università degli Studi di Firenze - Via S. Bonaventura 13, 50145 Firenze, Italy \\ ${ }^{3}$ Modena Province - Wildlife Service - Via Rainusso 144, Modena, Italy
}

\begin{abstract}
The restoration of longitudinal connectivity of a watercourse altered by man-made obstacles is a key issue for the protection and safeguard of freshwater ecosystems and the construction of fish passes constitutes a relevant ad hoc measure. However, in many countries, like Italy, there is still not an adequate technical-scientific background and experience in this field and therefore several migratory species have become extinct or are suffering from severe impacts. The main elements of the river rehabilitation for fish project promoted by the Modena Province concerning the middle course of the Panaro River (North Italy), a watercourse characterised by high naturalistic and environmental values but fragmented by several weirs built to prevent riverbed erosion, are presented in this paper. The case study is analysed through the main steps that were carried out to define a preliminary plan for the restoration of the river continuity for the migration of four target species (South European nase (Chondrostoma genei), Italian barbel (Barbus plebejus), chub (Leuciscus cephalus cabeda) and soufie (Leuciscus souffia muticellus)) through the design of an innovative type of steep-slope fish ramp with large-scale roughness elements. The case study is part of an overall project and is the applicative section of an "educational" document drawn up in the form of guidelines on the correct methodological approach for fish passes design, that will be addressed to professionals, technicians and local Authorities working in the field of water resource management.
\end{abstract}

Keywords: Fish passes, ichthyofauna, fish migration.

\section{INTRODUCTION}

Water withdrawals from watercourses and structures that interfere with fluvial riverbeds (weirs, road crossings, etc.) create a relevant factor of pressure on aquatic ecosystems, prevent the migration of fish species along the hydrographic network for trophic, reproductive and hibernation purposes and determine a fragmentation of the river continuum. The natural processes that involve exchanges of material and energy in watercourses can in fact be irreversibly compromised by the presence of man-made discontinuities: this is particularly due to the loss of natural habitat, that is, when fish populations that naturally colonise determined breeding areas and spawning grounds are enclosed within stretches downstream where they can undergo relevant impacts on their reproductive cycles. The consequence on the local ichthyic populations is an alteration of the original population, which can, in the most extreme cases, lead to the extinction of one or more species in the watercourse, and in particular of the diadromous species, with relevant repercussions on the biodiversity and equilibrium of the fluvial ecosystem. The restoration of longitudinal connectivity of a watercourse altered by man-made obstacles therefore constitutes a relevant objective for the protection and safeguard of freshwater ecosystems, and the main way this objective can be obtained is through the construction of fish passes.

The Italian legislative scenario relative to fish passes refers to two standards that date back to the first years of the last century: Royal Decree no. 1486 of 22 November, 1914 (Regulation on river and lake fishing) and Royal Decree no. 1604 of 8 October, 1931 (Approval of the text on fishing laws). These foresaw that, the for the release of water abstraction concessions ("the necessary works should be prescribed in the interest of the fishing industry" and that "whenever the construction of special structures for fish is not possible, the concessionaire can be prescribed annual introductions of juveniles at his expense". These prescriptions, however, have rarely been applied, especially as far as the construction of fish passes is concerned, while the obligation of the concessionaire to annually introduce juveniles has sometimes been encountered, in particular for structures on watercourses in which there is a significant interest in fishing (mainly for brown trout -Salmo trutta fario-) and where the local fishing associations have a certain weight.

Corresponding Author: Claudio Comoglio, DITAG (Dipartimento del Territorio, dell'Ambiente e delle Geotecnologie) Politecnico di Torino, c.so Duca degli Abruzzi 24, 10129 - Torino, Italy, 
More recently, with the introduction of national and regional standards concerning EIA (Environmental Impact Assessment) for new abstractions, the construction of such devices is gradually becoming a mitigating measure that is usually considered as part of Environmental Impact Studies, even though it is not supported by an adequate technical-scientific background that would allow correctly designed and efficient structures to be constructed in a widespread manner. In almost all cases, the constructions that can be found throughout the territory present evident and serious criticalities due to an erroneous or inadequate design and/or maintenance. In fact, unlike situations in other European (France, Great Britain, Germany, etc.) or American countries (Canada, the United States, etc.), because of the historical absence of stringent legal requirements concerning the construction of such devices, there is still an evident lack of research in this field at a national level, in particular regarding the "calibration" of fish passes as far as the biological requirements and swimming capabilities of the ichthyic species that characterise the Italian hydrographic network is concerned.

The result of this lack is that, from the beginning of the twentieth century till now, some migratory species have become extinct in several watercourses following the construction of most of the hydroelectric plants in Italy and due to the important increase in polluting loads carried by the water bodies. Some of the species that have become extinct are: some sturgeon (Acipenser sturio, Acipenser naccarii, Huso huso) and shad (Alosa fallax) in the Po River and in the most important river tributaries (the Panaro, Secchia, Adige, Ticino, etc.) while many other species have become rare and are at risk of extinction, such as the eel (Anguilla anguilla) in the Tyrrhenian watercourses, sea lamprey (Petromyzon marinus) and the European river lamprey (Lampetra fluviatilis).

It is in this scenario that the project of river rehabilitation for fish presented in this paper was carried out. The project, promoted by the Modena Province and developed through an analysis of a case study, concerns the middle course of the Panaro River (North Italy), and can be considered an innovative example in the national context.

The project had two main aims: to define a preliminary plan for the restoration of the longitudinal connectivity for fish migration in a watercourse that is characterised by high naturalistic and environmental values, but which has been fragmented by several weirs, and to use the case study as guidelines (something that is still lacking in Italy) for a correct methodological approach to fish pass design, which would mainly be for professionals, technicians and local Authorities working in the field of water resource management.

In this paper the main elements regarding the case study of the river restoration project through the design of fish passes at existing weirs are briefly presented.

\section{The study area}

The Panaro river (Fig. 1), with a length of $148 \mathrm{~km}$, a mean annual discharge of $37 \mathrm{~m}^{3} / \mathrm{s}$, and a watershed of $2,242 \mathrm{~km}^{2}$, is a tributary on the right side of the Po river that flows from the Apennine mountains. The study area covers a river reach of about $17 \mathrm{~km}$ between 170 and $290 \mathrm{~m}$ above sea level. The analyzed watershed is characterized by relevant environmental values and its lower portion is partially included in a Regional Natural Park, which is one of the most important naturalistic areas in the Emilia-Romagna Region. The middle course of this river was selected for the project case study because of its representativeness of the regional fluvial scenario (Tuscan-Emilian Apennines) in terms of hydrological and morphological characteristics and because of the relevance of the environmental features that have to be safeguarded and restored after the significant anthropic alterations that have occurred in the last decades.
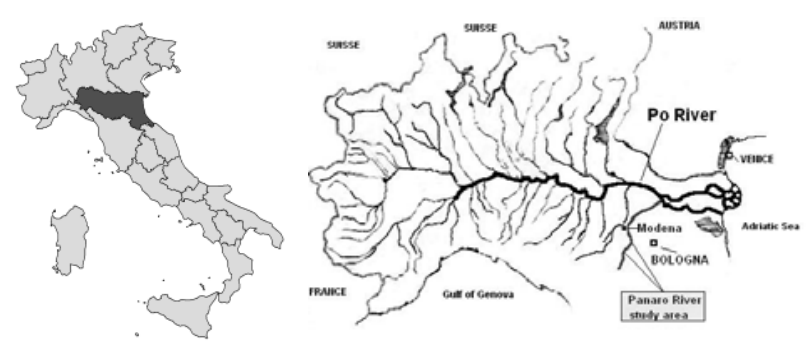

Fig 1: Panaro river watershed localization and study area.

Like almost all Apennine watercourses, several weirs and other anthropic intervention have significantly altered the natural morphology of the Panaro river ("anastomose channels"), interrupted fluvial continuity and prevented free circulation for fish. The entity of the environmental changes that this river has undergone in the lower sections (morphological alterations, pollution, introduction of allochthonous fish species, etc.) is such that it is almost impossible to imagine the restoration of a rich and complex ichthyic community which depended on the massive seasonal arrival of "marine" migratory species such as shad and eel, which penetrated (respectively for reproduction and growth) well within the mountain valleys from the Adriatic Sea through the Po river.

Nevertheless, the typical ichthyofauna in the middle course of the Panaro river still includes different fish species of local and European interest in terms of safeguard and conservation, in particular rheophylic Cyprinid species such as South European nase (Chondrostoma genei) and soufie (vairone - Leuciscus souffia muticellus), which require space to spawn and long fluvial reaches where it is possible for the population to seasonally move between the upper plain and the lower mountain. The interest in the middle 
course of the Panaro river is related to the fact that, while such fish species are still present there, the presence of several allochthonous species in the lower part of the river has greatly altered the local endemic communities while, in the upper zones, the local Salmonids populations have lost their genetic integrity due to restocking for sportfishing. Nevertheless some anthropic pressures are affecting the examined reach: fragmentation of the fluvial continuity can produce serious damage to the more mobile species which, prevented from moving towards the spawning areas, end up not reproducing or, even more likely, using suboptimal environments for this purpose with consequent less favourable reproductive successes. The damage due to the reproductive isolation of the sub-populations created on both sides of each anthropic obstacle is a further problem that involves not only the migrating species but also the entire ichthyic population, which includes more ecologically adaptable and permanent species, such as chub (Leuciscus cephalus cabeda) and Italian barbel (Barbus plebejus).
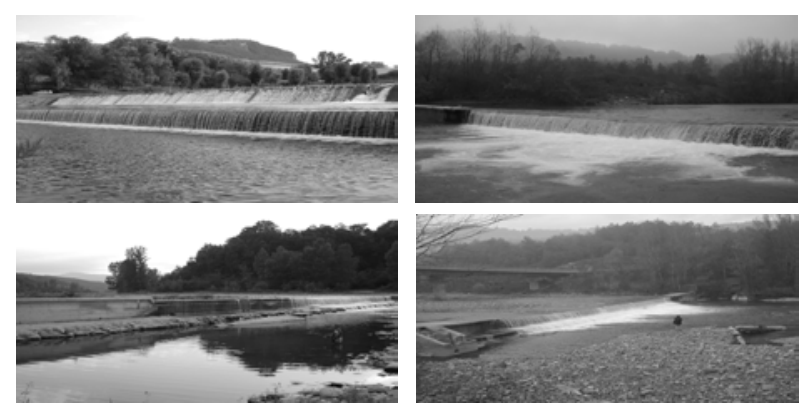

Fig 2: The Casona (A), Samone Bridge (B), Docciola Bridge (C) and Chiozzo Bridge (D) weirs.

In the reach under investigation, there are four important weirs (Fig. 2) that were built to prevent riverbed erosion, thus guaranteeing the stability of the same number of bridges. All of these are without fish passes. Going from the valley upwards, the weirs are those listed in Table 1.

Table 1: Examined weirs on the Panaro river.

\begin{tabular}{|c|c|c|c|}
\hline & Weirs & $\begin{array}{l}\text { Height } \\
(\mathrm{m})\end{array}$ & $\begin{array}{l}\text { Distance between weirs } \\
(\mathrm{m})\end{array}$ \\
\hline A & Casona & 3.50 & \\
\hline B & $\begin{array}{l}\text { Samone } \\
\text { Bridge }\end{array}$ & 1.10 & Casona - Samone B. 7'600 \\
\hline $\mathrm{C}$ & $\begin{array}{l}\text { Docciol } \\
\text { a Bridge }\end{array}$ & 1.80 & $\begin{array}{l}\text { Samone B. - Docciola B. } 6 \cdot 100 \\
\text { Docciola B. - Chiozzo B. } 3 \cdot 300\end{array}$ \\
\hline $\mathrm{D}$ & $\begin{array}{l}\text { Chiozzo } \\
\text { Bridge }\end{array}$ & 2.30 & \\
\hline
\end{tabular}

\section{MATERIALS AND METHODS}

The project was carried out through the main following steps: Analysis of the ichthyic community and identification of the target species: the first step was an analysis of the historical data on the ichthyofauna in this reach of the Panaro river; sampling data were available from three different surveys carried out in 1985, 1988 and in the 1998-2000 period.

As a second step, an ad hoc survey was carried out, with the following objectives: to update knowledge on the status of the local ichthyofauna and, at the same time, to integrate this with quantitative data that would permit the identification, thanks to a comparison with the previous data, of possible dynamics underway in the populations in the examined reach; to identify the target species, that is, the main reference species for the design of the fish passes; to define, with a sufficient degree of detail, the population structures of the individual species in order to identify the potentiality of use of the fish passes, in particular for the reproducers, and to allow their correct dimensioning.

The samplings were carried out using electrofishing apparatus, and the sampling sites were closed with a weir net in order to estimate the density and biomass values. Two electrofishing passages were usually considered sufficient to obtain a reliable estimation of the density using the Moran-Zippin method; only in some cases was a single passage considered sufficient to obtain a reliable estimation and an opportune correction factor, equal to the catchability value encountered with the subsequent passage method in nearby stations, was applied in the calculation stage.

The weight and total length of the caught specimens were measured to calculate the biomass and define the population structure of each species. The population structure was examined by dividing the sampled individuals into dimensional classes with reference to the total length with intervals equal to $1 \mathrm{~cm}$ between one class and another. The identification of the dimensional classes of the reproductive stock was deduced from a comparison with bibliographic data.

The target species for the design of the fish passes were selected according to the results of the above mentioned data, taking into account, for each sampled species, the migratory behaviour, the level of protection according to national and international laws and the inclusion in the national and international faunal lists of species at various risks of extinction (red lists of various European countries, the EC Habitat Directive, the Convention of Bern, etc.), and their population structure, comparing historical with up-to-date data in order to identify what species have suffered most from the river fragmentation by the examined weirs.

The migratory-reproductive periods of the selected target species were identified on the basis of bibliographic data, previous studies and observations in the regional watercourses.

The values of the maximum and cruising velocities were calculated using Videler equations [1], which supply values in relation to the length of the individuals, as no specific reference values were available concerning the swimming ability of the target 
species for the Apennine environments. The obtained values were then compared to the Habitat Suitability Curves versus the water velocity defined in previous studies for Italian barbel and chub in similar Italian watercourses.

Analysis of the river discharges in the examined river reach: a rainfall-discharge model set up by the EmiliaRomagna Region Environmental Protection Agency [2] supplied the data of interest for the examined reach for the Samone Bridge river section. These data were compared with direct measurements carried out by the National Hydrographic Service at an old hydrometer, which functioned from 1935 to 1940 for six years in a section further upstream, and with those at a new hydrometric station belonging to the Po river Watershed Authority. The data of the rainfall-discharge model were considered valid and representative for the entire reach under examination, as there are no important tributaries and it is relatively short. The mean monthly discharges and the discharges duration curve were used to identify the mean values expected during the migratory-reproductive season of the local ichthyofauna. Unfortunately no data on recurrence times for the duration curves were available.

Topography and hydrometric levels of the intervention area: detailed plans of the weirs and profiles and sections of the river reaches above and below the structures were obtained from their old design documentation and direct topographic surveys. During further surveys carried out in the migratory season the observed water levels upstream and downstream to/from the four structures were measured using a hydrometric rod and recorded. Water levels at the weirs were calculated considering the discharges expected during the target species migration season, including low flow and high flow conditions. Water levels in the river reaches upstream and downstream to/from the weirs were calculated through a one-dimensional hydraulic model (HEC-RAS) for a steady gradually varied flow.

Design of the fish passes: the discharge for the fish pass was chosen from an analysis of the Panaro river discharges during the migratory-reproductive season of the target species; in order to guarantee a sufficient attractivity of the fish pass for the upstream migrating fish, the minimum discharge for the device had to be selected in the $1 \%-5 \%$ range of values of the mean discharge of the migratory period [3].

The selected fish pass discharge and consequently the water velocities and energetic dissipation limits sustainable by the target species were then used as specific input to select the fish pass type to be used for the weir retrofitting design phase. The weirs features (use, height, width, etc.), the local hydrodynamic conditions (upstream and downstream water levels during the migration period, river morphology and solid transport, etc.) and a limited visual intrusion conditioned the final choice.

\section{RESULTS AND DISCUSISON}

The analysis of the historical data on the ichthyofauna of the Panaro river confirmed that the communities in the low course are significantly altered by the invasive presence of several allochthonous species and the local features of the Salmonids populations of the high course are compromised by the genetic pollution caused by repopulation. The ichthyic population in the middle course (study area) is instead rather well conserved, from the qualitative point of view, except for a serious lack of long range migratory species, like shad, due to the presence of several obstructions in the path from the Adriatic Sea. The $17 \mathrm{~km}$ long examined reach can be classified, in terms of fish zonation, as a rheophylic Cyprinids zone. From a conservation point of view, almost all the fish that make up the local ichthyofauna are considered of national and European Community importance, such as South European nase, Italian barbel, soufie, together with spined loach (Cobitis taenia), common goby (Padogobius martensii), and gudgeon (Gobio gobio). A serious decrease in number and a progressive habitat reduction, in particular as far as the most ecologically demanding species are concerned, was highlighted from historical data; a remarkable decrease in the number of South European nase has in particular been documented throughout the territory over the last 20 years.

The direct samplings with electrofishing apparatus were carried out on 13, 14 and 15 July 2005; the examined reach was divided into 5 sub-reaches bounded by the Casona, Samone Bridge, Docciola Bridge and Chiozzo Bridge weirs, where sub-reach 1 the Panaro was river reach immediately downstream from the Casona weir (first downstream structure) and sub-reach 5 the last upstream reach, just above the Chiozzo Bridge weir (last upstream structure). The stations where the ichthyic sampling was to be performed were chosen on the basis of accessibility and of their environmental representativeness in comparison to the characteristics of each sub-reach. This led to different stations being sampled within the same sub-reach, taking into consideration the mean values of the different ichthyologic parameters for calculation purposes. A total of nine stations were therefore sampled (1 station for sub-reaches 1 and 3, 2 stations for sub-reaches 4 and 5 and 3 stations for sub-reach 2).

Seven species were found: South European nase, Italian barbel, chub, soufie, gudgeon, rainbow trout (Oncorhynchus mykiss), and common goby. The most 

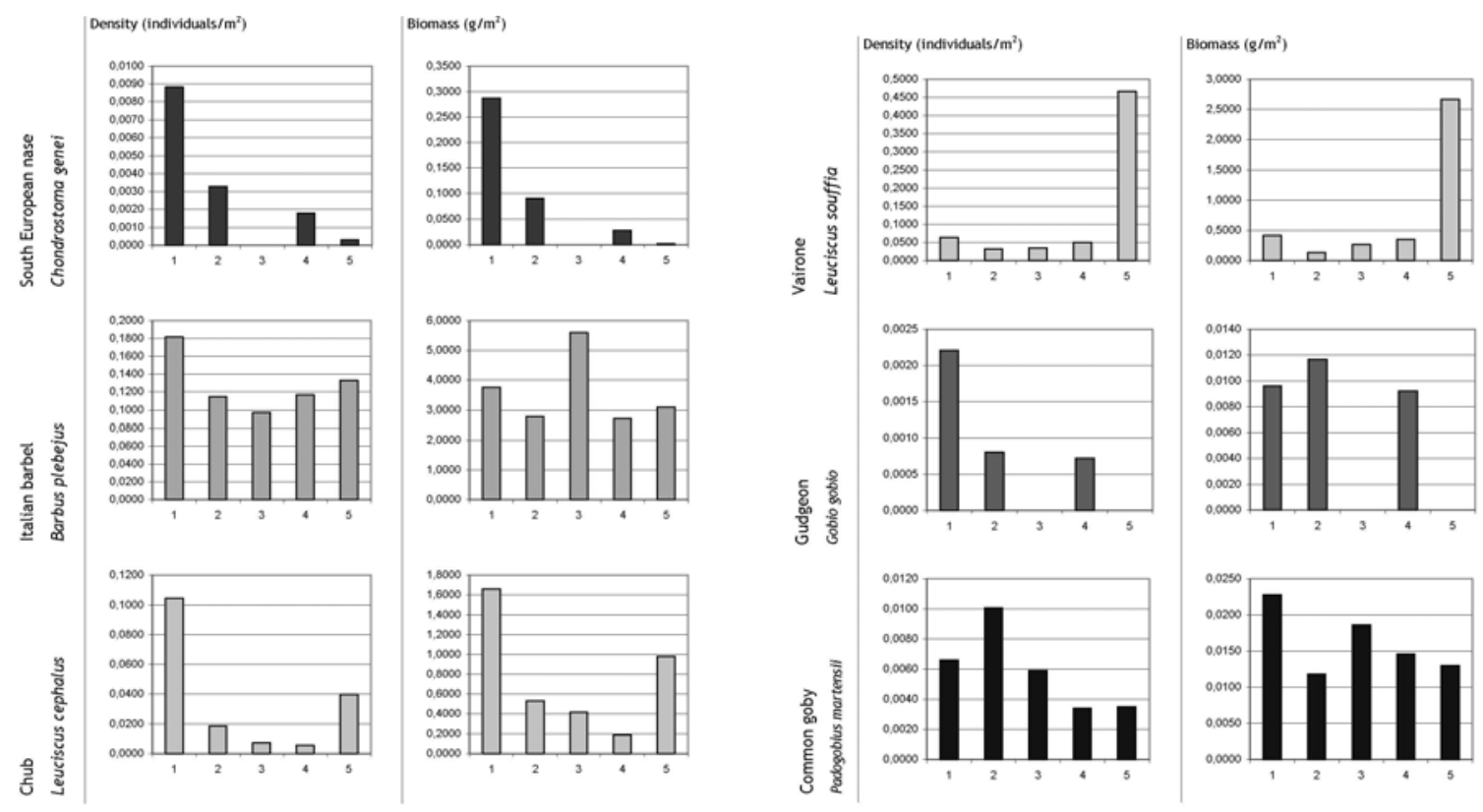

Fig 3: Density and biomass values of the fish species sampled in the examined sub-reaches (1-5).

common species, and at the same time the most representative in terms of biomass, was Italian barbel, while the presence of rainbow trout was completely random, as only one specimen was found in only one sampling station (sub-reach 4) probably due to drift from the upstream river reaches.

The density (individuals $/ \mathrm{m}^{2}$ ) and biomass $\left(\mathrm{g} / \mathrm{m}^{2}\right)$ values obtained for each species in the five sub-reaches are reported in Fig. 3.

South European nase have extremely low density and biomass with the same degrading trend towards higher altitudes. The population structure seems impossible to evaluate because of the extremely low number of individuals that were caught. Recruitment seems to be absent or almost absent. The sizes vary between 6 and $20 \mathrm{~cm}$. The presence of this species at much higher altitudes than those examined (information obtained from previous data) and in greater density, demonstrates that the progressive rarefying of the species in the investigated sectors cannot be attributed to general ecological conditions. Furthermore, the investigations performed in further downstream reaches revealed a massive presence of the species. This situation would suggest that the interruption of the fluvial continuity is contributing, in a significant way, to the decline of this species which, given the high conservational value, can be assumed as the main target species for the case-study.

Italian barbel is the most represented species, in terms of biomass, in all the considered sections, while its density is only exceeded by that of soufie in the last upstream sub-reach (no 5). No particularly evident differences were observed in the various sectors: the populations are well structured everywhere, even though recruitment generally seems to be rather poor. On the basis of what is known from literature, the reproducers belong to age classes equal to or higher than $2+$ for the males and $3+$ for the females. The frequency peak distribution of the dimension classes of the examined populations indicates that these age classes correspond to dimensions greater than about 10 $\mathrm{cm}$. In spite of the fact that no particular conservation problems are present, the species can be considered as a target species as it remarkably characterises, from the ecological point of view, the examined reach, but also because it is a highly mobile species for trophic and reproductive purposes.

Though quite common in the examined reach, chub have a rapidly decreasing density and biomass, compared with those surveyed in 1988 in the examined reach. The population structure is well balanced in the different dimension classes in the downstream subreaches 1 and 2. A progressive disappearance, first of the specimen with larger dimensions followed by the younger ones, starts from sub-reach 3 . There is a certain levelling out of the frequency in the dimension classes above $8 \mathrm{~cm}$ and this makes it difficult to identify frequency peaks. It was considered sufficiently cautionary to set $10 \mathrm{~cm}$ as the minimum dimension of the reproducers (age classes 2+ and above). Although chub cannot be considered at risk, it should be included in the target species as it markedly characterises the examined section and, at the same time, is undergoing a slight decrease in number. 
Am. J. Environ. Sci., 3 (3): 85-92, 2007

Table 2: Panaro river mean monthly discharges

\begin{tabular}{ccccccccccccc}
\hline Month & Jan & Feb & Mar & Apr & May & Jun & Jul & Aug & Sep & Oct & Nov & Dec \\
$\begin{array}{c}\text { Discharges } \\
\left(\mathrm{m}^{3} / \mathrm{s}\right)\end{array}$ & 17.13 & 13.35 & 13.48 & 19.31 & 11.41 & 9.29 & 3.50 & 2.24 & 8.65 & 22.38 & 26.6 & 18.70 \\
\hline
\end{tabular}

Table 3: Panaro river discharges duration curve

\begin{tabular}{lllllllllllll}
\hline Duration (days) & 1 & 5 & 10 & 20 & 30 & 60 & 91 & 135 & 182 & 274 & 355 & 365 \\
$\begin{array}{l}\text { Discharges } \\
\left(\mathrm{m}^{3} / \mathrm{s}\right)\end{array}$ & 165 & 76.5 & 53.5 & 40.6 & 31.8 & 21.11 & 15.93 & 11.39 & 8.30 & 3.94 & 1.41 & 1.18 \\
\hline
\end{tabular}

Soufie is well represented both in terms of density and biomass in all the considered sub-reaches. There is a relevant increase in its presence in sub-reach 5 , which is probably connected to general ecological factors. The zone with the highest vocationality for the species is in fact located at the upper border of the rheophylic Cyprinids zone. The population structure appears in general to be well balanced. The age classes above 1+ are distributed around the frequency peak of $9 \mathrm{~cm}$. The high level of representativeness of soufie is therefore confirmed for the examined reach and should be included in the target species, also because of its marked mobility characteristics.

Gudgeon is a very rare species. A comparison with recent data (1998-2000) has not shown any remarkable change in its status.

Common goby is relatively frequent in the considered reach. The density and biomass of the species undergoes a certain decrease towards the higher altitude sub-reaches. The populations overall are well structured, with good levels of recruitment, at least in the lower sub-reaches.

On the basis of the collected data, South European nase, Italian barbel, chub and soufie were selected as "target species", as they are the most representative fish species and are characterized by migratory behaviour and, especially for South European nase and chub, are affected by the weirs.

The examination of the length classes of the collected specimens allowed the population structure of these species of rheophylic Cyprinids to be defined and the dimensional range of the breeders, real target of the fish passes, to be identified: the minimum length was therefore fixed at $10 \mathrm{~cm}$, a threshold that includes most of the breeders of all the target species.

This length was then used in the Videler equations to calculate the values of the maximum and cruising velocities for the target species, which resulted to be $1.14 \mathrm{~m} / \mathrm{s}$ and $0.4 \mathrm{~m} / \mathrm{s}$ respectively.

The calculated values are approximate because no direct experimental reference values were available for the considered species in the Apennine environments, and because the swimming ability depends on a series of factors (physical state and health, water temperature, etc.) that can be faced by fish while migrating; they were nevertheless considered as an adequate and precautionary reference for the hydraulic design of the fish passes.

The reproductive period of the selected target species in the Apennine watercourse ranges from between May and July, but consistent movements can occur even in April, August and September. The whole AprilSeptember period was then taken into account for the fish passes design.

The mean monthly discharges and the discharges duration curve of the Panaro river obtained from the rainfall-discharge model carried out by the EmiliaRomagna Region Environmental Protection Agency, and considered as a representative reference for the entire reach under examination, are outlined in Tables 2 and 3. Raw data for the calculation of the discharges recurrence times for different durations were not available.

The possibility of a partial or total removal of the obstacles that prevent the ichthyofauna migration was considered unfeasible because the examined weirs play a fundamental role in hydraulic safety by protecting the piers of the upstream bridges against erosion processes that could be caused by the action of the current and the removal of these structures would therefore be a highly risky intervention for the stability of the road infrastructures.

Sudden changes in discharge are frequent in the Panaro river, as also revealed during direct surveys, and it is also characterized by high solid transport (watershed mean specific erosion $=0.14 \mathrm{~mm} /$ year; solid transport total capacity $=154 \cdot 10^{3} \mathrm{~m}^{3} /$ year) which could cause remarkable management difficulties for continuous ordinary maintenance of the new devices. Structures as self cleaning as possible and able to absorb the excursions in water level without affecting the upstream migration were therefore a necessary choice.

The Panaro river average discharge in the target species migration period (April-September) is $9 \mathrm{~m}^{3} / \mathrm{s}$ and therefore the minimum discharge of the fish passes should consequently be from $90 \mathrm{l} / \mathrm{s}$ up to $450 \mathrm{l} / \mathrm{s}$, values usually guaranteed in the watercourse during the whole mean hydrological year, being lower than the 365 days duration discharge $\left(1.18 \mathrm{~m}^{3} / \mathrm{s}\right)$. It should be outlined that, in recent years, there has been an increase in 
droughts and new hydropower projects have been proposed along the regional river network: therefore discharges lower than the previous values could be expected even for prolonged periods.

The first downstream weir (Casona) differs from the three other weirs because of its different structure (a "box" weir with two subsequent jumps) and a higher drop $(3.50 \mathrm{~m})$; furthermore a new hydropower station project is foreseen to retrofit this structure. A preliminary design of the fish pass was therefore not completed due to the fact that the hydropower project details were not yet available (as well as the values of the discharges that will be withdrawn and compulsorily released as environmental flow). However the attractivity of the fish pass (a vertical slot typology was suggested) is a key-point that will be taken into account during the Environmental Impact Assessment procedure: the compulsory instream flow will have to be released either completely through the fish pass or, in order to limit its dimensions and related costs, through a proper device (pipe, channel) as an auxiliary flow that will not compete with the remaining discharge flowing through the fish pass.

The other three weirs have important elements in common, which were further analyzed through the acquisition of their design documentation and direct topographic surveys:

- $\quad$ modest height ( $\Delta \mathrm{h}$ between 1.10 and $2.30 \mathrm{~m}$ );

- large transversal development (of the order of about 80-100 linear m);

- planimetric geometry and central position of the principal stream of the current.

For this reason, a similar typology of fish pass was studied for these three obstacles to migration: the chosen typology consisted of a fish ramp delimited by stone and concrete side walls, with a bottom substrate made of river-bed material and perturbation boulders homogeneously placed along the whole length of the passage in order to create macro-roughness that dissipates the kinetic energy of the flow (reducing velocities and increasing water levels to levels that can be adequately faced by the target fish species) and mimick the structural variety of a fluvial habitat (different flow lines and velocity gradients, creation of micro-refuges, colonization of the bottom substrate by aquatic macroinvertebrates).

The preliminary design of the fish ramps at the Samone Bridge, Docciola Bridge and Chiozzo Bridge weirs was based on the innovative results of recent studies developed by Larinier and Chorda [4] at the Institut de Mécanique des Fluides de Toulouse through laboratory tests on physical models of that typology, with significant bottom slopes and homogeneous distributions of the perturbation boulders.

The selected typology was then adapted to the main operational needs related to the local peculiarities:

- to limit the length of the fish passes (bottom slope increase), guaranteeing sustainable hydrodynamic conditions according to the swimming capabilities of the target species;

- to keep the main channel (and consequently the fish pass) in the middle of the river section both for hydraulic safety and fish pass attractivity reasons;

- to concentrate the whole flow in the fish pass during dry periods, guaranteeing its efficiency even for discharges lower than the 365 days duration discharge.

For this last aspect a lateral bottom slope (5\%) was designed in order to guarantee proper water levels for the ichthyofauna at least at one side of the pass.

Therefore the main parameters of the proposed fish pass (Fig. 4) were:

- Bottom slope: $5 \%$

- Lateral slope: 5\%

- Width: $4.5 \mathrm{~m}$

- Boulders diameter: $0.60 \mathrm{~m}$

- Boulders height: $1.00 \mathrm{~m}$
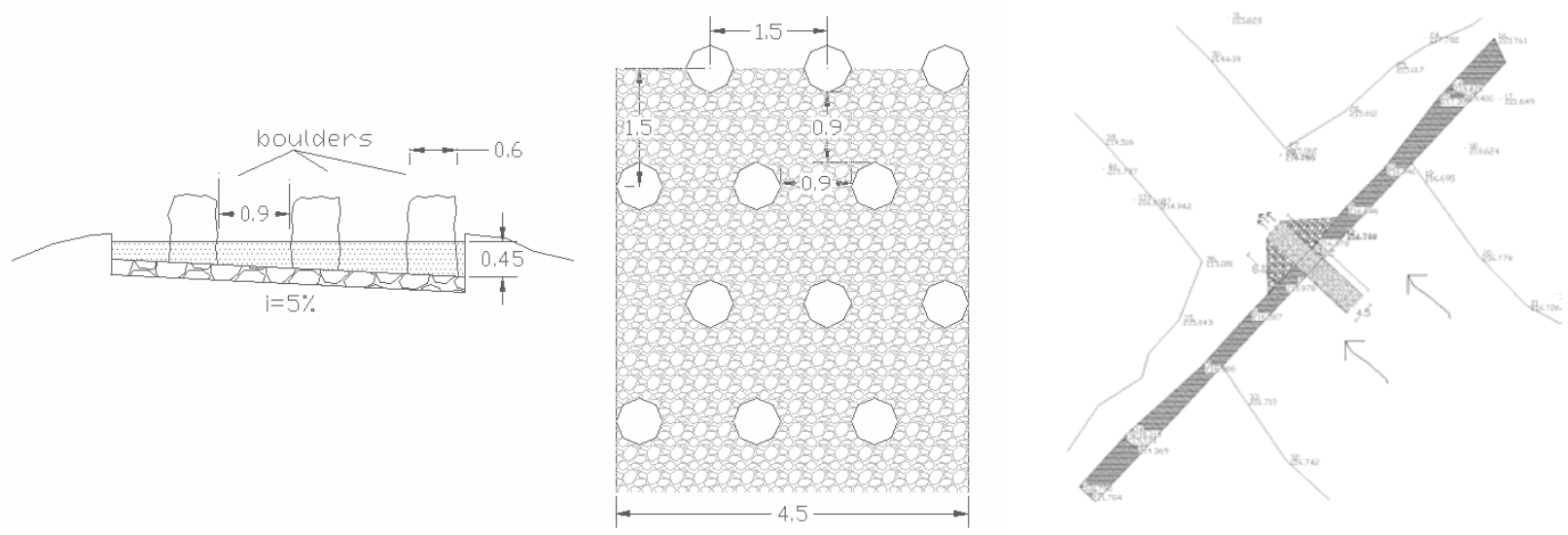

Fig 4: Operational model: schematic section, plan view and insertion at the existing weir. 
- $\quad$ Bottom substrate diameter: $>0.20 \mathrm{~m}$

This typology of fish pass was considered as the operational model that can be used for all the three weirs, working for discharges varying from $450 \mathrm{l} / \mathrm{s}$ (upper limit of the minimum fish pass discharges range), up to an optimal discharge of $1.27 \mathrm{~m}^{3} / \mathrm{s}$. For higher discharges the activation of flow above the weir crest and on two lateral rock aprons, designed for the fish pass banks stability, is expected. The water depth and flow velocity values for the discharges of $450 \mathrm{1} / \mathrm{s}$ and $1.27 \mathrm{~m}^{3} / \mathrm{s}$ are $0.25 \mathrm{~m}$ and $0.45 \mathrm{~m}$, and $0.73 \mathrm{~m} / \mathrm{s}$ and $0.91 \mathrm{~m} / \mathrm{s}$ respectively. Considering the different flow lines and velocity gradients created by the boulders, the hydrodynamic conditions of the fish pass can be considered adequately sustainable by the target species. The analysis carried out in this project and briefly presented in this paper has led to the definition of a preliminary plan for the restoration of the longitudinal connectivity for fish migration in the middle course of the Panaro river through the design of an operational fish pass model considered suitable for the local features.

The chosen fish ramp typology, based on the innovative results of recent French studies on physical models of steep-slope flows above large-scale roughness elements, will in fact be able to maintain hydrodynamic conditions that can be faced by rheophylic Cyprinids and will not require continuous maintenance works due to the relevant solid transport of the Panaro river. Furthermore the limited length of the fish passes, due to the significant bottom slope $(5 \%)$, as well as their position in the middle of the weirs crest, will reduce construction costs (a bottom ramp for the entire weir width was considered unfeasible) thus guaranteeing hydraulic safety of the structures. The proposed solution will therefore be well inserted into the environmental and countryside context, which is characterised by relevant naturalistic and environmental values.

The fish samplings carried out during the study supplied an important update on the status of the local ichthyofauna with quantitative data on density, biomass and population structures and dynamics; the progressive decrease in number, especially for South European nase, outlines the need for river rehabilitation works on this watercourse. The data supplied will be crucial in order to obtain the financial resources needed to carry out the final design and the construction of the proposed fish passes on the Panaro river from the competent Authorities.

The monitoring of their efficiency, whose methodological steps has already been defined in the project (fish trapping in the upstream section of each fish pass and electrofishing surveys in the 5 subreaches), will significantly contribute to increase the present poor knowledge of the swimming ability and migratory behaviour of the examined fish species and will show objective evidence of the environmental results that could be obtained through the construction of such mitigation measures to all the stakeholders involved in the water resource management policies.

However the study of the swimming ability of autochthonous fish species and the monitoring of fish passes efficiency shall be key issues in scientific research in this field at a national level in future years.

Through the analysis of the case study, which is relevant at a local level, the river rehabilitation for fish project was structured as guidelines on the correct methodological approach to fish pass design [5], describing each phase of this process step by step, starting from the preliminary hydrological and environmental studies of the site up to the fish pass monitoring and maintenance programme. Such an "educational" document was lacking in the Italian context, and was therefore intended for professionals, technicians and local Authorities working in the field of water resource management in order to increase their awareness and competences in this field.

The complete final report, already divulged by Modena Province to all the national and regional competent Authorities, is now under examination by FAO (Food and Agriculture Organization of the United Nations) in order to be included in their technical papers: the Italian situation in the field of river rehabilitation for fish and fish pass construction, is in fact representative of that of many other countries throughout the world, and therefore this project has been identified as a good reference to develop similar initiatives in analogous situations.

\section{ACKNOWLEDGEMENTS}

The Authors wish to thank Modena Province for the financial support and data availability, Dr. Gerd Marmulla (FAO - Inland Water Resources and Aquaculture Service) and Dr. Michel Larinier (Director of GHAAPPE - Groupe d'Hydraulique Appliqué aux Aménagements Piscicoles et à la Protection de l'Environnement) for their involvement and continuous support at the implementation of the project, and Dr. Enrico Marconato and Dr. Giuseppe Maio (AIIAD Italian Association of Freshwater Ichthyologists) for their contribution in the analysis of the data concerning ichthyofauna.

\section{REFERENCES}

1. Videler J., 1993. Fish swimming. Fish and fisheries series 10. Chapman \& Hall, 260 p.

2. ARPA Regione Emilia-Romagna, 2003. Modello afflussi-deflussi sul reticolo idrografico naturale principale del territorio regionale.

3. Larinier M., Travade F., Porcher J.P., 2002. Fishways: biological basis, design criteria and monitoring. Bull. Fr. Pêche Piscic, 364 suppl. FAO, CSP, Cemagref, 208 p.

4. Chorda J., Larinier M., Thinus Z., 2004. A flume study of steep-slope flows above large-scale roughness elements and their application to fish passes. In: Proceedings of Fifth International Symposium on Ecohydraulics, Madrid, 12-17 September 2004.

5. Pini Prato E., Gianaroli M., Ferri M., Comoglio C., Marconato E., Maio G., Marmulla G., Larinier M., 2006. Linee guida per il corretto approccio metodologico alla progettazione di passaggi per pesci. Ed. Provincia di Modena, pp. $135^{+}$ appendice.

6. FAO, 1998. Rehabilitation of rivers for fish. FAO, $260 \mathrm{pp}$.

7. FAO/DVWK., 2002. Fish passes. Design, dimensions and monitoring. FAO, $119 \mathrm{p}$.

8. Comoglio C., Pini Prato E., Rosso M., 2006. Proposta di linee guida per l'adeguamento delle opere di presa esistenti al rilascio del deflusso minimo vitale. Regione Piemonte, $159 \mathrm{p}$. 